\title{
Cognitive Neuro-Rehabilitation of HIV-Associated Neurocognitive Disor- ders: Case Reports of A New Computer-Based Restorative Approach In 3 Hiv-Positive Cart-Treated Patients
}

Francesca Iannuzzi ${ }^{1, *}$, Francesca Bai ${ }^{1}$, Lidia Borghi ${ }^{2}$, Mattia Trunfio ${ }^{1}$, Elena Anna Maria Vegni ${ }^{2}$, Antonella d'Arminio Monforte ${ }^{1}$ and Giulia Marchetti ${ }^{1}$

${ }^{1}$ Clinic of Infectious and Tropical Diseases, Department of Health Sciences, University of Milan, San Paolo Hospital, Milan, Italy

${ }^{2}$ Unit of Clinical Psychology, Department of Health Sciences, University of Milan, San Paolo Hospital, Milan, Italy

${ }^{*}$ Corresponding authors: Francesca Iannuzzi, Clinic of Infectious and Tropical Diseases, Department of Health Sciences, University of Milan, San Paolo Hospital, Milan, Italy. Tel +39 0281843046; Fax +39 0281843054; E-mail francesca.iannuzzi@hotmail.it

Received Date: October 23, 2016; Accepted Date: November 18, 2016; Published Date: November 22, 2016

Citation: Francesca Iannuzzi, et al. (2016) Cognitive Neuro-Rehabilitation of Hiv-Associated Neurocognitive Disorders: Case Reports of A New Computer-Based Restorative Approach In 3 Hiv-Positive Cart-Treated Patients. J Neurophysiol Neurol Disord 3: 1-5.

\begin{abstract}
At enrolment (T0) three on combination antiretroviral therapy (cART) HIV-positive patients with HIV Associated Neurocognitive Disorders (HAND) were enrolled to undergo a computer-based rehabilitation program (https://dynamicbrain. brainhq.com/) for 12 weeks, under the supervision of a physician. At the end (T1), the patients were tested again with a neuropsychological battery. Patient 1 (current CD4 T-cell count 405/mmc, HIV-RNA <40UI/ml) had a diagnosis of mild neurocognitive disorders (MND) at T0 and normal evaluation at T1. Patient 2 (current CD4 T-cell count 366/mmc, HIV$\mathrm{RNA}<40 \mathrm{UI} / \mathrm{ml}$ ) had asymptomatic neurocognitive disorders (ANI) at T0 and normal performance at T1. Patient 3 (current CD4 T-cell count 522/mmc, HIV-RNA <40UI/ml) had MND at T0 and normal performances at T1. Patients' adherence to the program was $100 \%$. Our pilot experience with a computer-based restorative approach showed good results in term of improvement in neuropsychological performances in treated HIV+ patients. These data suggest the need to explore innovative ways to manage HAND.
\end{abstract}

\section{Background}

HIV-infected patients undergoing long-term combination antiretroviral therapy (cART) present an increased risk of morbidity/mortality due to clinical complications typically associated with aging, including cardiovascular disease, cancer, osteoporosis and cognitive impairment [1]. 20-50\% of patients on cART still display minor forms of HIV-associated neurocognitive disorders (HAND), like asymptomatic neurocognitive impairment (ANI) and mild neurocognitive disorders (MND) [2]. HAND is characterized by impairments in several cognitive domains leading to poor cART adherence, regardless of other neuropsychiatric factors [3]. Considering the consequences of HAND, novel strategies to handle cognitive impairment still remain an unmet clinical need and should be a priority.
Due to the lack of an optimal pharmacotherapy for HAND, researchers have investigated the possibility of cognitive rehabilitation. In the last years three pilot studies investigating computerized rehabilitation on HIV-infected patients have been published [4-6] all these studies have adopted a restorative approach. Even if their outcome was not the resolution of HAND, but the improvement of specific neurocognitive functions, their initial results were encouraging. Given a recent report by Livelli et al.[7] showing the efficacy and stability over time of a cognitive rehabilitation protocol in treated HIV-positive patients with HAND, we hereby describe our experience on the efficacy of a new computer-based program in $3 \mathrm{HIV}$-positive patients on cART. 


\section{Materials and Methods}

We consecutively enrolled $3 \mathrm{HIV}$-positive patients on stable cART from a larger cohort who underwent a complete neuropsychological battery in the contest of a dedicated outpatient service for the diagnosis and follow-up of HAND. Inclusion criteria were $\geq 18$ years of age, history of HAND according to Frascati's criteria [8], being on stable cART ( $>6$ months) with plasma HIV-RNA $<40 \mathrm{UI} / \mathrm{ml}$, regardless of CD4+ T-cell count. Exclusion criteria were history of CNS diseases, psychiatric disorders, drug addiction in the last 12 months, alcohol abuse.

The Institutional Review Board approved the study, and all the patients signed a written consent form. At enrolment (T0), the patients underwent a complete neuropsychological battery composed by tests covering seven different cognitive domains: speed of information processing [Trail Making Test Part A, Symbol Digit Modality Test, Stroop Color Test - Time]; learning and memory [Rey Auditory Verbal Learning Test Immediate Recall and Delayed Recall, Rey Osterrieth complex Delayed Recall]; abstraction/executive functioning [Stroop Color Test - Error, Trail Making Test Part B (TMTB)]; language [Semantic and Phonemic Fluency]; attention/ working memory [Corsi's block Tapping Test, Forward and Backward Digit span, Trail Making Test Part BA]; motor skills [Finger Tapping Test]; sensory/perceptual [Rey Osterrieth complex Figure Copy]. The functional assessment was evaluated through the instrumental abilities in daily living (IADL) and Short Form-36 (SF-36) for quality of life; anxiety and depression symptoms were explored by the Hospital Anxiety and Depression Scale (HADS). Raw scores on each test were calculated. Scores were corrected for age, educational level and gender using Italian normative data. In particular, the raw scores were first adjusted and then transformed into new standardized scores (named Equivalent Scores, ES) on an ordinal scale ranging from 0 (pathological performance) to 4 (best performance) [9]. The HAND diagnosis was established according to the Frascati's criteria [8].

The patients underwent 12 sessions of a computer-based rehabilitation program, a novel brain plasticity-based computerized cognitive training (https://dynamicbrain.brainhq.com/), adopting a restorative approach. Previous studies demonstrated the efficacy of this program $[10,11]$ in improving generalized measures of memory and attention and in maintaining long-term effects among the elder general population. Given these encouraging data, the neuropsychologist selected a panel of exercises from the training program; the selected exercises stimulated the skills of the cognitive domains that are most frequently impaired in HAND [8]. The 17 selected exercises were: divided attention, target tracker, double decision, mixed signals, freeze frame, hawk eye, visual sweeps, eye for detail, memory grid, scene crasher, syllable stacks, face facts, card shark, juggle factor, right turn, mental map and optic flow. Each exercise was automatically administered in different steps with progressively increasing difficulty. Each session lasted one hour once a week for three months, under the supervision of a physician.
The physician scheduled each session according to patient's availability, helped patients to use the program and explained how to perform the exercises. Two weeks after the end of the program (T1), the patients were re-tested with HADS, IADL, SF36 and the same neuropsychological battery using parallel forms for those tests which test-retest reliability is over three months, in order to control for the potential confounding 'practice effect'.

\section{Results}

All patients were Caucasian males; two patients had previous AIDS-defining events without central nervous system involvement. One subject had diabetes mellitus with good glycemic control on oral hypoglycemic therapy; no other known comorbidities, including viral hepatitis co-infection, were present. Table 1 shows features of the performances at T0 and T1 for each patient. Table 2 shows the functional assessment for each patient at $\mathrm{T} 0$ and $\mathrm{T} 1$.

Patient 1 was 58 years old; at the time of examination CD4+ T-cells were $405 / \mathrm{mmc}$, with undetectable HIV-RNA. Nadir CD4+ T-cells was $5 / \mathrm{mmc}$. Time from the first HIV diagnosis was 174 months and the patients was on cART for 173 months. At T0 the patient complained of cognitive decline and he was diagnosed with MND: he showed deficit in two different cognitive domains (attention/working memory and motor skills) and an altered IADL score. After 12 weeks of cognitive rehabilitation (T1) the patient improved, according to Frascati's criteria: only one cognitive domain (motor skill) remained altered. He also presented a normal IADL and HADS anxiety score.

Patient 2 was 40 years old; he presented a CD4+ T-cells count of $366 / \mathrm{mmc}$ with a CD4+ T-cells nadir of $183 / \mathrm{mmc}$ and a HIV-RNA $<40 \mathrm{UI} / \mathrm{ml}$; time from the first HIV diagnosis was 14 months, while cART duration was 12 months. He had ANI at T0: two different cognitive domains were altered (memory and executive functioning) in absence of symptoms. At T1 he restored normal neurocognitive performance, reaching the normal equivalent score in each neuropsychological test.

Finally, patient 3 was 36 years old with CD4+ T-cells of 522/ mmc, CD4+ T-cells nadir of 96/mmc and HIV-RNA <40 UI/ $\mathrm{ml}$. Time from the first HIV diagnosis was 19 months and he was on cART for 15 months. This patient complained of cognitive decline and displayed a diagnosis of MND at T0: he had deficits in 3 different cognitive domains (speed of information processing, motor skills and executive functioning) and an altered IADL score. At T1 the patient improved reaching normal performance according to Frascati's criteria: he showed only one altered domain (speed of information processing), without symptoms and he had normal IADL score. Moreover, patient 3 had an improvement of SF36 score. Patients' adherence to the program was $100 \%$. 


\begin{tabular}{|c|c|c|c|c|}
\hline PATIENT 1 & RAW SCORE (T0) & $\begin{array}{l}\text { EQUIVALENT SCORE } \\
\text { (T0) }\end{array}$ & RAW SCORE (T1) & $\begin{array}{l}\text { EQUIVALENT SCORE } \\
\text { (T1) }\end{array}$ \\
\hline Digit Span Test direct/reverse & $3 / 3$ & $0 / 0$ & $7 / 4$ & $4 / 1$ \\
\hline $\begin{array}{l}\text { Rey Auditory Verbal Learn- } \\
\text { ing Test/ }\end{array}$ & $41 / 7$ & $4 / 3$ & $48 / 7$ & $4 / 3$ \\
\hline recalling Trial making & $26.5 / 106.48$ & $4 / 4$ & $38 / 91.09$ & $4 / 4$ \\
\hline test $\mathrm{A} / \mathrm{B}$ Trial making & 79.98 & 4 & 53.09 & 4 \\
\hline $\begin{array}{l}\text { test B-A Symbol Digit Mo- } \\
\text { dality Test }\end{array}$ & 38 & 2 & 43 & 2 \\
\hline Finger tapping test right/left & $40.6 / 30.2$ & $0 / 0$ & $42.8 / 39.8$ & $0 / 0$ \\
\hline $\begin{array}{l}\text { Fluency test (phonemic)/ } \\
\text { (semantic) }\end{array}$ & $23 / 50$ & $2 / 4$ & $33 / 47$ & $4 / 4$ \\
\hline $\begin{array}{l}\text { Stroop Color Word Interfer- } \\
\text { ence Test (time)/error }\end{array}$ & $31.58 / 1$ & $2 / 3$ & $20.15 / 1.5$ & $4 / 3$ \\
\hline PATIENT 2 & $\begin{array}{l}\text { RAW SCORE } \\
\text { (T0) }\end{array}$ & $\begin{array}{l}\text { EQUIVALENT } \\
\text { SCORE (T0) }\end{array}$ & $\begin{array}{l}\text { RAW } \\
\text { SCORE (T1) }\end{array}$ & $\begin{array}{l}\text { EQUIVALENT } \\
\text { SCORE }(\mathrm{T} 1)\end{array}$ \\
\hline Digit Span Test direct/reverse & $8 / 8$ & $4 / 4$ & $7 / 5$ & $4 / 2$ \\
\hline $\begin{array}{l}\text { Rey Auditory Verbal Learn- } \\
\text { ing Test/recalling }\end{array}$ & $46 / 5$ & $3 / 0$ & $57 / 7$ & $4 / 1$ \\
\hline Trial making test $\mathrm{A} / \mathrm{B}$ & $27.12 / 50.62$ & $4 / 4$ & $20.76 / 58.23$ & $4 / 4$ \\
\hline Trial making test B-A & 23.5 & 4 & 37.47 & 4 \\
\hline Symbol Digit Modality Test & 59 & 2 & 66 & 2 \\
\hline Finger tapping test right/left & $63.4 / 51.4$ & $>1 />1$ & $58.2 / 46.6$ & $>1 />1$ \\
\hline $\begin{array}{l}\text { Fluency test (phonemic)/ } \\
\text { (semantic) }\end{array}$ & $48 / 62$ & $4 / 4$ & $32 / 63$ & $3 / 4$ \\
\hline $\begin{array}{l}\text { Stroop Color Word Interfer- } \\
\text { ence Test (time)/ (error) }\end{array}$ & $15 / 3$ & $2 / 0$ & $9.71 / 0$ & $4 / 3$ \\
\hline PATIENT 3 & $\begin{array}{l}\text { RAW } \\
\text { SCORE (T0) }\end{array}$ & $\begin{array}{l}\text { EQUIVALENT } \\
\text { SCORE (T0) }\end{array}$ & $\begin{array}{l}\text { RAW } \\
\text { SCORE (T1) }\end{array}$ & $\begin{array}{l}\text { EQUIVALENT } \\
\text { SCORE (T1) }\end{array}$ \\
\hline Digit Span Test direct/reverse & $4 / 4$ & $1 / 1$ & $6 / 4$ & $4 / 1$ \\
\hline $\begin{array}{l}\text { Rey Auditory Verbal Learn- } \\
\text { ing Test/ }\end{array}$ & $44 / 10$ & $3 / 3$ & $47 / 7$ & $4 / 1$ \\
\hline recalling Trial making & $39,32 / 139.56$ & $4 / 3$ & $32.56 / 60.37$ & $4 / 4$ \\
\hline test A/B Trial making & 100,24 & 2 & 27.81 & 4 \\
\hline $\begin{array}{l}\text { test B-A Symbol Digit Mo- } \\
\text { dality Test }\end{array}$ & 29 & 0 & 27.81 & 0 \\
\hline Finger tapping test right/left & $39.2 / 46$ & $0 / 0$ & $43.8 / 52$ & $>1 />1$ \\
\hline $\begin{array}{l}\text { Fluency test (phonemic)/ } \\
\text { (semantic) }\end{array}$ & $30 / 48$ & $3 / 4$ & $20 / 43$ & $1 / 4$ \\
\hline $\begin{array}{l}\text { Stroop Color Word Interfer- } \\
\text { ence Test (time)/(error) }\end{array}$ & $23.9 / 7$ & $2 / 0$ & $12.5 / 0$ & $4 / 3$ \\
\hline
\end{tabular}

Legend: equivalent score: $0=$ pathologic, $\geq 1=$ normal

Table 1: Patients' neurocognitive performances at T0 and T1 


\begin{tabular}{|l|l|l|}
\hline PATIENT 1 & $\begin{array}{l}\text { SCORE AT } \\
\text { T0 }\end{array}$ & $\begin{array}{l}\text { SCORE AT } \\
\text { T1 }\end{array}$ \\
\hline IADL & 7 & 8 \\
\hline HADS A/D & $12 / 3$ & $7 / 1$ \\
\hline SF-36 PSS/MSS & $1 / 0$ & $1 / 0$ \\
\hline PATIENT 2 & SCORE AT & SCORE AT \\
\hline IADL & 8 & 8 \\
\hline HADS A/D & $1 / 0$ & $0 / 0$ \\
\hline $\begin{array}{l}\text { SF-36 } \\
\text { PSS/MSS }\end{array}$ & $0 / 0$ & $0 / 0$ \\
\hline PATIENT 3 & SCORE AT & \\
\hline T0 & SCORE AT 1 \\
\hline HADS A/D & $0 / 1$ & 8 \\
\hline SF-36 & $0 / 1$ & $0 / 1$ \\
\hline PSS/MSS & & $0 / 0$ \\
\hline
\end{tabular}

Legend: IADL altered if $<8$, HADS A altered if $\geq 12$, HADS $D$ altered if $\geq 12$, SF- 36 PSS and MSS altered if 1 . HADS A= anxiety score; HADS D= depression score; SF-36 PSS= physical sum score; SF-36 MSS= mental sum score.

Table 2: Functional assessment for each patient

\section{Discussion}

The absence of an optimal first-line pharmacotherapy for HAND has led researchers to explore cognitive and behavioral approaches. The neurorehabilitation is known to be useful in the management of other forms of dementia, like Alzheimer's and Parkinson's disease, and to prevent senile cognitive decline [12]. Typically, the cognitive rehabilitation approaches are divided in two categories: restorative and compensatory. Compensatory rehabilitation aims to minimize the cognitive deficits by helping the patient to develop and learn new strategies to overcome the impairment (e.g. people with poor memory can have a small slip to write down what they need to remember). The compensatory approach is mainly used for rehabiliting deficits after a stroke or a traumatic brain injury, by stimulating perilesional or controlateral homologous areas and their corresponding functions. Restorative approaches rely upon the principle of neuroplasticity and propose that "drill-and-practice" of cognitive skills will encourage more effective neural organization and ultimately improved impaired cognitive abilities. In fact, restorative rehabilitation aims to enable the person to develop the lost function through specialized computerized and manual cognitive exercises.

All the previous three pilot studies investigating cognitive rehabilitation on HIV-infected patients [4-6] adopted a restorative approach, while Livelli at al. used a compensatory approach. In our study we chose the brainHQ program (Posit Science Inc, San Francisco, US), a restorative approach tool, given previous data in preventing senile cognitive decline in a long time follow-up [12]. Furthermore, this program is available in eight different languages and can therefore be reproduced in different geographical settings.

In the previous studies on HIV-positive patients, the interventional program was self-administered at the research center or at patient's home, resulting in limited adherence. In order to improve patients' adherence, we chose a one session-per-week formula under the supervision of a physician in a short time period (12 weeks). We obtained $100 \%$ of adherence with this scheme. Importantly, all patients were very motivated to participate to the program suggesting the importance of a good motivational pre-intervention counselling. Although in a small group of 3 patients, with no power to detect statistically significant differences, we hereby describe an improvement in HAND through a new computer-based tool of cognitive rehabilitation in the setting of treated HIV infection. In particular, we show an improvement in the executive functioning, attention/working memory, memory and motor skills. Future research with larger samples should be performed to evaluate the efficacy of our restorative computer-based program in improving other cognitive domains. Moreover, we observed an improvement in daily life activities, with a better quality of life and a reduction of anxiety symptoms. This outcome suggests that improving cognitive functions could result in a better emotional wellbeing and that a frequent interaction between patients and physician can reduce psychological apprehension of people living with HIV.

\section{Conclusions}

Our experience supports the need to explore innovative ways to manage HAND in HIV-infected patients. A study with a large cohort should be designed to assess the real effectiveness and feasibility of a computer-based neurocognitive approach in the management of this HIV-related comorbidity. Furthermore, a short and long-term follow-up will be necessary to determine the durability of the rehabilitation program's outcome.

\section{Acknowledgments}

We are thankful to all the patients and their families who took part to the study. This work was supported by Gilead Fellowship program 2012 (\#F61bd8c044) 


\section{References}

1) Deeks SG (2011) HIV infection, inflammation, immunosenescence, and aging. Annu Rev Med 62:141-155.

2) Heaton RK, Franklin DR, Ellis RJ, McCutchan JA, Letendre SL, et al. (2011) HIV-associated neurocognitive disorders before and during the era of combination antiretroviral therapy: differences in rates, nature, and predictors. J Neurovirol. 17: 3-16.

3) Ammassari A, Antinori A, Aloisi MS, Trotta MP, Murri R, et al. (2004) Depressive symptoms, neurocognitive impairment, and adherence to highly active antiretroviral therapy among HIV-infected persons. Psychosomatics 45: 394-402.

4) Boivin MJ, Busman RA, Parikh SM, Bangirana P, Page CF, et al. (2010) A pilot study of the neuropsychological benefits of computerized cognitive rehabilitation in Ugandan children with HIV. Neuropsychology. 24: 667-673.

5) Becker JT, Dew MA, Aizenstein HJ, Lopez OL, Morrow L, et al. (2012) A pilot study of the effects of internet-based cognitive stimulation on neuropsychological function in HIV disease. Disabil Rehabil 34:1848-1852.

6) Vance DE, Fazeli PL, Ross LA, Wadley VG, Ball KK (2012) Speed of processing training with middle-age and older adults with HIV: a pilot study. J Assoc Nurses AIDS Care. 23: 500-510.

7) Livelli A, Orofino GC, Calcagno A, Farenga M, Penoncelli D, et al. (2015) Evaluation of a Cognitive Rehabilitation Protocol in HIV Patients with Associated Neurocognitive Disorders: Efficacy and Stability Over Time. Front Behav Neurosci.9:306.

8) Antinori A, Arendt G, Becker JT, Brew BJ, Byrd DA, et al. (2007) Updated research nosology for HIV-associated neurocognitive disorders. Neurology 69: 1789-1799.

9) Capitani E, Laiacona M (1997) Composite neuropsychological batteries and demographic correction: standardization based on equivalent scores, with a review of published data. The Italian Group for the Neuropsychological Study of Ageing. J Clin Exp Neuropsychol 19: 795-809.

10) Smith GE, Housen P, Yaffe K, Ruff R, Kennison RF, et al. (2009) A cognitive training program based on principles of brain plasticity: results from the Improvement in Memory with Plasticity-based Adaptive Cognitive Training (IMPACT) study. J Am Geriatr Soc 57: 594-603.

11) Wolinsky FD, Mahncke H, Vander Weg MW, Martin R, Unverzagt FW, et al. (2010) Speed of processing training protects self-rated health in older adults: enduring effects observed in the multi-site ACTIVE randomized controlled trial. Int Psychogeriatr 22: 470-478.

12) Rebok GW, Ball K, Guey LT, Jones RN, Kim HY, et al. (2014) Ten-year effects of the advanced cognitive training for independent and vital elderly cognitive training trial on cognition and everyday functioning in older adults. J Am Geriatr Soc. 62: 16-24.

\section{Submit your manuscript to a JScholar journal} and benefit from:

๑ Convenient online submission

ฯ Rigorous peer review

ๆ Immediate publication on acceptance

ब Open access: articles freely available online

ฯ High visibility within the field

ब Better discount for your subsequent articles

Submit your manuscript at http://www.jscholaronline.org/submit-manuscript.php 